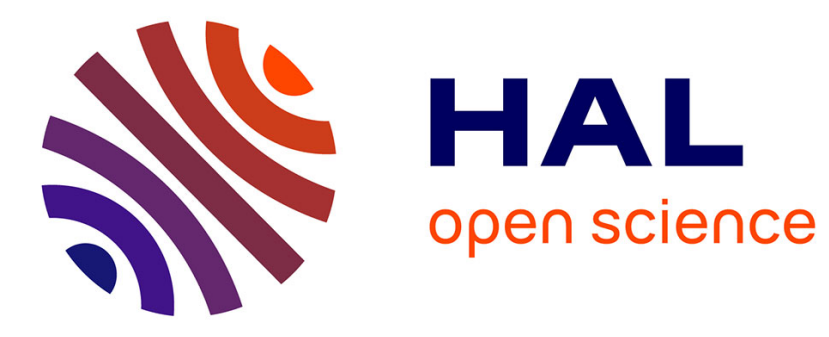

\title{
Dual color localization microscopy of cellular nanostructures
}

\author{
Manuel Gunkel, Fabian Erdel, Karsten Rippe, Paul Lemmer, Rainer \\ Kaufmann, Christoph Hörmann, Roman Amberger, Christoph Cremer
}

\section{To cite this version:}

Manuel Gunkel, Fabian Erdel, Karsten Rippe, Paul Lemmer, Rainer Kaufmann, et al.. Dual color localization microscopy of cellular nanostructures. Biotechnology Journal, 2009, 4 (6), pp.927. 10.1002/biot.200900005 . hal-00494027

\section{HAL Id: hal-00494027 \\ https://hal.science/hal-00494027}

Submitted on 22 Jun 2010

HAL is a multi-disciplinary open access archive for the deposit and dissemination of scientific research documents, whether they are published or not. The documents may come from teaching and research institutions in France or abroad, or from public or private research centers.
L'archive ouverte pluridisciplinaire HAL, est destinée au dépôt et à la diffusion de documents scientifiques de niveau recherche, publiés ou non, émanant des établissements d'enseignement et de recherche français ou étrangers, des laboratoires publics ou privés. 


\section{Dual color localization microscopy of cellular nanostructures}

\begin{tabular}{|r|l|}
\hline Journal: & Biotechnology Journal \\
\hline Manuscript ID: & biot.200900005.R2 \\
\hline Wiley - Manuscript type: & Research Article \\
\hline Date Submitted by the & 10 -May-2009 \\
\hline Complete List of Authors: & $\begin{array}{l}\text { Gunkel, Manuel; University Heidelberg, Kirchhoff-Institute for } \\
\text { Physics } \\
\text { Erdel, Fabian; Deutsches Krebsforschungszentrum, Research Group } \\
\text { Genome Organization and Function } \\
\text { Rippe, Karsten; Deutsches Krebsforschungszentrum, Research } \\
\text { Group Genome Organization and Function } \\
\text { Lemmer, Paul; University Heidelberg, Kirchhoff-Institute for Physics } \\
\text { Kaufmann, Rainer; University Heidelberg, Kirchhoff-Institute for } \\
\text { Physics } \\
\text { Hörmann, Christoph; University Heidelberg, Kirchhoff-Institute for } \\
\text { Physics } \\
\text { Amberger, Roman; University Heidelberg, Kirchhoff-Institute for } \\
\text { Physics } \\
\text { Cremer, Christoph; University Heidelberg, Kirchhoff-Institute for } \\
\text { Physics }\end{array}$ \\
\hline Keywords: & $\begin{array}{l}\text { SPDM, localization microscopy, molecular imaging, } \\
\text { nanobiophotonics, 2CLM }\end{array}$ \\
\hline \hline
\end{tabular}

\section{今) ScholaroNE" \\ Manuscript Central}


1

2

3

4

5

6

7

8

9

10
Research Article ((6366 words))

\section{Dual color localization microscopy of cellular nanostructures}

\author{
Manuel Gunkel ${ }^{1}$, Fabian Erdel ${ }^{2}$, Karsten Rippe ${ }^{2}$, Paul Lemmer ${ }^{1}$, Rainer Kaufmann ${ }^{1}$, \\ Christoph Hörmann ${ }^{1}$, Roman Amberger ${ }^{1}$, Christoph Cremer ${ }^{1,3,4^{*}}$
}

${ }^{1}$ Kirchhoff-Institute for Physics \& BioQuant Center University of Heidelberg, Im Neuenheimer Feld 227, D-69120 Heidelberg, Germany

${ }^{2}$ Deutsches Krebsforschungszentrum \& BioQuant Center University of Heidelberg, Research Group Genome Organization \& Function, Im Neuenheimer Feld 280, D-69120 Heidelberg, Germany

${ }^{3}$ Institute for Pharmacy and Molecular Biotechnology, University of Heidelberg, Im Neuenheimer Feld 364, D-69120 Heidelberg, Germany

4 Institute for Molecular Biophysics, The Jackson Laboratory, 600 Main Street, Bar Harbor, ME 04609, USA

*corresponding author: cremer@kip.uni-heidelberg.de

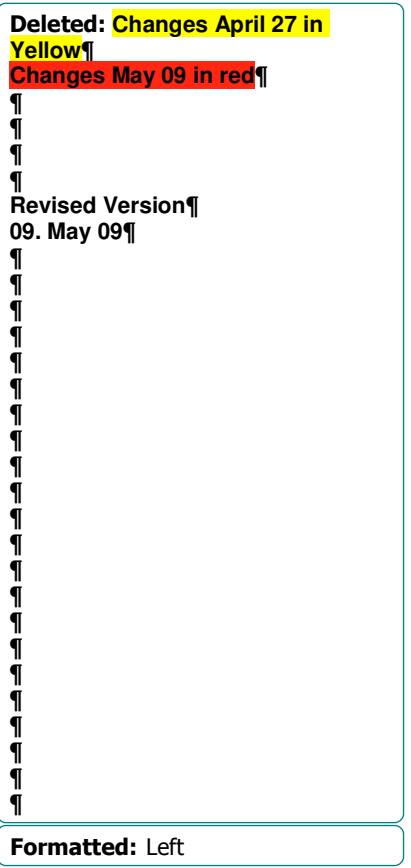




\section{ABSTRACT}

The Dual Color Localization Microscopy (2CLM) presented here is based on the principles of Spectral Precision Distance Microscopy (SPDM) with conventional fluorochromes under special physical conditions. This technique allows us to measure the spatial distribution of single fluorescently labeled molecules in entire cells with an effective optical resolution comparable to macromolecular dimensions. Here, we describe the application of the 2CLM approach to the simultaneous nanoimaging of cellular structures using two fluorochrome types distinguished by different fluorescence emission wavelengths. The capabilities of 2CLM for studying the spatial organization of the genome in the mammalian cell nucleus are demonstrated for the relative distributions of two chromosomal proteins labeled with autofluorescent GFP and mRFP1 domains. The 2CLM images revealed quantitative information on their spatial relationships down to length-scales of $30 \mathrm{~nm}$.

Keywords: 2CLM, SPDM, localization microscopy, molecular imaging, nanobiophotonics, superresolution fluorescence microscopy, chromatin, spectrally assigned localization microscopy (SALM)

\section{INTRODUCTION}

About 170 years ago, light microscopy facilitated the discovery of the cell as the fundamental unit of life, thus initiating one of the great revolutions of human science (for review see [1]). In the development of modern cell biology and its biomedical applications, however, analysis methods using visible light microscopy approaches often played a secondary role compared with biochemical techniques. A major reason for this was the optical resolution thought to be restricted to a fundamental limit of a few hundreds of $\mathrm{nm}$ laterally (and about $600 \mathrm{~nm}$ axially). Consequently, the nanostructure of cellular machines (e.g. the protein complexes responsible for molecular transport, DNA replication, transcription and repair, RNA splicing, protein synthesis and degradation), was not accessible to light microscopy. The same is true for the spatial organization of specific chromatin domains with a size in the hundred $\mathrm{nm}$ range that play an essential role for gene regulation [2]. As described in the famous publication of Ernst Abbe (1873) [3], this limit in light-optical resolution of about $200 \mathrm{~nm}$ was thought to be due to the wave nature of light ; it was regarded to be insurmountable according to the fundamental laws of physics. A very similar conclusion was obtained in 1896 by Lord Rayleigh [4]. However, a variety of laseroptical far field microscopy techniques based on fluorescence excitation has been developed recently to circumvent the Abbe/Rayleigh-limit of $200 \mathrm{~nm}$. These make lightoptical analysis of biological macromolecules by enhanced resolution possible. Some well known methods are 4Pi-Microscopy [5-6], structured/patterned illumination microscopy $[7,8]$, STED microscopy $[9,10]$ and spectrally assigned localization microscopy (SALM) approaches using far field fluorescence microscopy [11-28, 49 - 52]. With these techniques, an effective optical resolution in the $10-20 \mathrm{~nm}$ regime has been obtained. While STED microscopy is a focused beam method that allows it to rapidly image small regions of 
interest (few $\mu \mathrm{m}$ extension), the complementary localization microscopy techniques are preferentially used in a non-focusing setup for rapidly imaging large regions of interest (50 $-100 \mu$ m extension).

The basis of SALM as a far field fluorescence microscopy approach is the independent localization of "point-like" objects excited to fluorescence emission by either focused or non-focused illumination techniques, typically with a laser. This means the localization is achieved by appropriate features of the fluorochromes resulting in an "optical isolation". We refer to this approach as "Spectral Precision Distance (Position Determination) Microscopy" (SPDM). SPDM was already conceived and realized in proof-of-principle experiments in the 1990s [11 - 16,19]. Compared with related concepts [29 - 31], the SPDM approach relies on specific spectral signatures including all kinds of fluorescent emission parameters suitable, from absorption/emission spectra to fluorescence life times [13] to luminescence in general.

In the last few years, SALM methods have been improved considerably by several groups by making use of photoswitchable fluorochromes. In these approaches, fluorochromes are switched between a 'dark' state $A$ and a 'bright' state $B$ using a first laser wavelength $\lambda_{1}$ for switching from $A$ to $B$ and a second laser wavelength $\lambda_{2}$ from $B$ to $A$. In this way, the position of the molecules was determined with precision values significantly better than the full width at half maximum (FWHM). These microscopic techniques were termed photoactivated localization microscopy (PALM) [20], fluorescence photoactivation localization microscopy (FPALM) [21], stochastic optical reconstruction microscopy (STORM) [22], PALM with independently running acquisition (PALMIRA) [23, 24], or "direct" STORM (dSTORM) [27]. In all these approaches, special fluorochromes were used which can be photoswitched between a "dark" state A and a "bright" state B [6].

Recently, we applied SPDM on the nanometer resolution scale to conventional fluorochromes. In contrast to the photoswitching based SALM methods cited above, one laser wavelength only is used to induce fluorescence/luminescence lifetimes in a given fluorochrome on the second time scale. In this case under special physical conditions "reversible photobleaching" [25, 26, 28] occurs. "Reversible photobleaching" has been shown to be a general behavior in several fluorescent proteins, e.g. GFP derivates like CFP, GFP, Citrine or eYFP [34 - 36]. Under such conditions, the fluorescence emission of certain types can be described by assuming three different states of the molecule: $A$ fluorescent state $M_{\mathrm{fl}}$, a long living reversibly bleached state $\mathrm{M}_{\mathrm{rb}}$, and an irreversibly bleached state $M_{\mathrm{ibl}}$. Once the molecule returns from the $\mathrm{M}_{\mathrm{rbl}}$ state to the $\mathrm{M}_{\mathrm{fl}}$ state, it can be excited a large number of times (fluorescence bursts) until it passes into the irreversibly bleached state $M_{\text {ibl }}$ (i.e. a dark state of a lifetime which is long compared with the acquisition time [34, 37]); and thus its position can be determined with nanometer precision

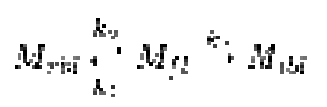

[25,26, 28]. With transition time constants $k_{1}, k_{2}, k_{3}$ one can assume the transition scheme [34]. We recently showed that reversible photobleaching can be used for superresolution imaging of cellular nanostructures labeled with conventional fluorochromes such as Alexa 
$488[25,37]$ or the Green Fluorescent Protein variant YFP [26]. This novel extension of the SPDM approach to ordinary fluorophores was based on the possibility to produce the optical isolation required by allowing only one molecule in a given observation volume and in a given time interval to be in the $M_{\mathrm{fl}}$ state. Such conditions were achieved by using an excitation intensity in the $10 \mathrm{~kW} / \mathrm{cm}^{2}$ to $1 \mathrm{MW} / \mathrm{cm}^{2}$ range. These conditions were equivalent to switching the majority of the fluorophores to a metastable dark state and allowing the spontaneous return to lower energy levels under the emission of fluorescence photons [49]. Recently, Foelling et al. [49] have described a related approach to obtain highly resolved dual-color images of immunostained microtubules and peroxysomes using Atto 532 and 565 dyes. Here we present first results to extend the SPDM method to the localization of two different molecule types in human cell nuclei ("Two color localization microscopy", 2CLM). Two types of nuclear proteins tagged with two different standard fluorescent proteins were distinguished by different fluorescence emission wavelengths. 2CLM was applied to "nanoimage" the spatial distribution of these proteins at molecular optical resolution.

The organization of the DNA genome by proteins is a particular interesting subject for 2CLM microscopy studies. In the cell nucleus the DNA is compacted by histone proteins into a nucleoprotein complex termed chromatin [38]. The central building block of chromatin is the cylindrically shaped nucleosome (11 nm diameter, $5.5 \mathrm{~nm}$ height). It comprises an octamer core of two copies each of histones $\mathrm{H} 2 \mathrm{~A}, \mathrm{H} 2 \mathrm{~B}, \mathrm{H} 3$ and $\mathrm{H} 4$ around which the DNA is wrapped in 1.67 turns. In the present study the technique of 2CLM microscopy was used to determine the intracellular location of chromatin remodeling complexes with respect to chromatin. Chromatin remodelers are molecular machines that can translocate nucleosomes along the DNA sequence upon hydrolysis of ATP [39-42]. By making use of autofluorescent constructs of histone $\mathrm{H} 2 \mathrm{~A}$ as a nucleosome/chromatin marker and the ATPase subunit Snf2H [41 - 43] that defines a certain class of chromatin remodeling complexes, their nuclear localization was analyzed with an estimated mean localization accuracy in the range of about $20 \mathrm{~nm}$ (ca. 1/25 of the excitation wavelength). The results indicate the feasibility to reveal details on the interaction of remodeling complexes with chromatin at unprecedented effective resolution.

\section{MATERIAL AND METHODS}

\subsection{Specimen preparation}

Human U2OS osteosarcoma cells were cultured on 12-mm diameter glass coverslips in Dulbecco's Modified Eagle medium supplemented with $10 \%$ FCS for 1 day after plating. Cells were transiently transfected with plasmid vectors for Snf2H-GFP and H2A-mRFP1 using Effectene (Qiagen) according to standard protocols. After transfection, cells were cultured for 1 day, fixed in $4 \%$ paraformaldehyde and then embedded with Mowiol 4-88 (Roth) as mounting medium. The plasmid pEGFP-N3-Snf2H was kindly provided by Patrick Varga-Weisz and contains the full coding sequence of human Snf2H fused to GFP at the C-terminus [43]. The plasmid pRSET-H2A-mRFP1 contains the full coding sequence of 
human $\mathrm{H} 2 \mathrm{~A}$ with the red fluorescent mRFP1 domain at the C-terminus [Jegou, T. (2007) PhD Thesis, University Heidelberg].

\subsection{Microscope setup}

In Fig. 1 the principal setup is shown schematically.

Due to the "bright" initial state $\left(\mathrm{M}_{\mathrm{fl}}\right)$ of the fluorochromes, specimens can be imaged in a standard far-field conventional epifluorescence mode as well as in the 2CLM mode. The specimens were illuminated by an $\mathrm{Ar}^{+}$-laser at $\lambda_{\mathrm{exc}}=488 \mathrm{~nm}$ (excitation of GFP) or a $\mathrm{Kr}^{+}$laser at $\lambda_{\mathrm{exc}}=568 \mathrm{~nm}$ (excitation of mRFP1), which were focused by the lens system L1 L3 and an objective lens 100x/NA1.4, oil (Leica, 35578 Wetzlar, Germany). This focusing was modified in such a way that fluorescent molecules in the observation volume were exposed to illumination intensities in the order of $50-200 \mathrm{~kW} / \mathrm{cm}^{2}$ ) within a broad region of interest. The degree of focusing and thus the laser power density was adjusted by varying the distances within the lens system along the optical axis. Under these conditions, suitable fluorochromes as GFP and mRFP1 exhibited their characteristic reversible photobleaching or light induced blinking, which was used to identify and spatially assign the localization of individual molecules. Up to 70000 single molecules were detected in a region of interest of about $20 \mu \mathrm{m} \times 20 \mu \mathrm{m}$. Using a sensitive CCD camera (PCO, 93309 Kehlheim, Germany) with a quadratic pixel size of $6.45 \mu \mathrm{m} \times 6.45 \mu \mathrm{m}(1376 \times 1040$ pixels total) with a quantum efficiency of up to $65 \%$ for image acquisition, time series of $2 \mathrm{D}$ - images were acquired with a repetition rate between $10-16 \mathrm{~Hz}$. A typical time stack of 1500 images was typically acquired within approximately 2 min. For further details, see [28].

An estimation of the chromatic shift was obtained by imaging fluorescently labeled $100 \mathrm{~nm}$ beads under the same conditions used for the acquisition of 2CLM images. The positions were determined in both channels and compared to each other. The mean chromatic shift was found to be $5.6 \pm 2.3 \mathrm{~nm}$ (see supplementary methods).

\subsection{Software for data registration and evaluation}

The microscopy data recorded were stored on a computer hard disk and evaluated later by algorithms implemented in MATLAB (7.0.1, The MathWorks, Natick, USA), a matrix based programming language for numerical computations. The algorithms were designed to handle the data with high background noise and large variation of background due to bleaching of the fluorochromes (e.g. dense labeling, large observation/activation volume) as well as for a low noise scenario with negligible bleaching (e.g. photoactivatable molecules in PALM/FPALM and/or small excitation volumes). The algorithm calculates the following quantities [26, 28]:

- The position of the fluorescence signal in the object plane/in the object space

- Estimates for the localization accuracy (parameter errors are the diagonal elements of the covariance matrix at convergence) on the single molecule level

- The characteristic parameters of the model function used to determine single molecule positions 
- Estimates for the number of detected photons per molecule as a decisive parameter of localization microscopy

- The position of the detected signal (individual molecule) in the data stack (i.e. image frame number) to analyze the influence of time and to extract relevant characteristics of the fluorochromes used

Following signal detection and registration, in a second step an optional preprocessing was performed. While signals with high signal-to-noise ratio (low background) can be used as raw data for the following data segmentation, in case of high background and photobleaching effects active during several succeeding image frames, an additional computing step was performed to segment signals originating from single molecules only. For this a differential photon stack $D_{P h}\left(x, y, t^{\prime}\right)=S_{P h}\left(x, y, t_{k+1}\right)-S_{P h}\left(x, y, t_{k}\right)$ between two successive image frames (registered at $t_{k}$ and $t_{k+1}$ ) was calculated. The error $\sigma$ in photon number produced by the Poisson statistics of the incident photons and the noise $\sigma_{C C D}$ of the CCD sensor detection (approx. 4 counts per pixel) was estimated by the Gaussian law

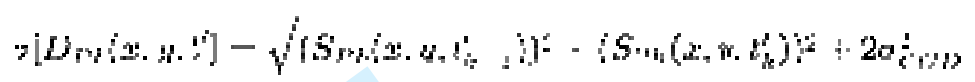

of error propagation,

The data stacks $S_{P h}(x, y, t)$ (in case of low background) and $D_{P h}\left(x, y, t^{\prime}\right)$ (in case of high background) were then used for high precision localization of single molecules (lateral) by adapting modified Gaussian model functions. To reduce the computing efforts, Regions of Interest (ROls) of typically $8 \times 8$ pixels were used, containing the signal.

Then a two dimensional Gaussian with a background gradient

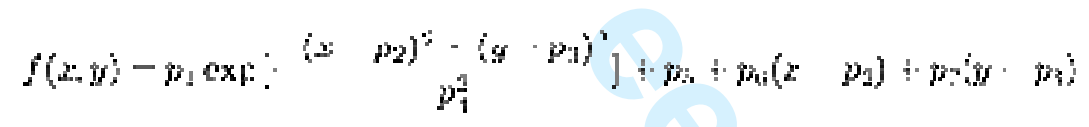

was fitted to the thresholded signals.

An appropriate set of values $p_{1}-p_{7}$ was used as start parameters which were then optimized by the application of a Levenberg-Marquardt algorithm.

The final results were analyzed for parameter plausibility by additional filters. In this way molecules were localized in an observation volume with a thickness corresponding to an 'optical section' of $600 \mathrm{~nm}$. For further details see [28].

\section{RESULTS}

3.1 The label density is critical for 2CLM experiments 
To test the effects of the localization accuracy and the density of fluorescent molecules on the appearance of the "nanoimages" obtained by 2CLM, the evaluation algorithms described above were applied to simulated data. As an example, results obtained from a simulated structure are presented. For this, the letters "2CLM" were scaled to an overall length of $2 \mu \mathrm{m}$ and a height of $0.4 \mu \mathrm{m}$ (first row in Fig. 2). These four letters were then simulated to contain single molecules with various densities $\left(50000,5000\right.$ and $500 / \mu \mathrm{m}^{2}$ ) with a "fluorescence burst" emission. From these original images, conventional epifluorescence images and 2CLM images were calculated as described elsewhere [28].

The result is presented in the second row of Fig. 2. The diffraction-limited widefield image shows some alterations in the intensity distribution and gives an estimate of the overall size of the "nanostructure". A reconstruction of the original object, however, is clearly not possible by assuming a "conventional" resolution (calculated PSF using numerical aperture of $1.4,100 \mathrm{~nm}$ effective pixel size of the detector and $520 \mathrm{~nm}$ (560 nm red letters) as emission wavelength).

In the third row of Fig. 2 the image is shown for the application of the 2CLM approach assuming a mean localization accuracy of $20 \mathrm{~nm}$; a comparison with the original "nanostructure" demonstrates the substantial resolution improvement. The third row shows the simulation results for a localization accuracy of $10 \mathrm{~nm}$. At a high $\left(50000 / \mu^{2}\right)$ or medium $\left(500 / \mu \mathrm{m}^{2}\right)$ molecule density, the original "2CLM nano-object" can be fully reconstructed. At a "low" molecule density, basic structural features can still be identified. To summarize, the simulations show a) that the 2CLM method indeed allows us to extract structural information far below the conventional resolution limit of epifluorescence microscopy, b) that the density of molecules is a critical parameter, depending on the structure to be studied.

\subsection{Nuclear distributions of H2A and Snf2H could be determined by 2CLM}

The lateral distribution of mRFP1 labeled $\mathrm{H} 2 \mathrm{~A}$ and GFP labeled $\mathrm{S}$ nf $2 \mathrm{H}$ proteins in human U2OS nuclei was determined by 2CLM within "optical sections" of about $600 \mathrm{~nm}$ thickness in about 20 cells. These sections result from the fact, that the PSF of objects outside of the focal plane is broadened up and thus has a worse signal-to-noise ratio $(\mathrm{S} / \mathrm{N})$. Accordingly, these signals were filtered out by the fitting algorithm. In the mean, around 1,200-1, 800 photons per molecule were detected.

Figure 3 shows the distribution of mRFP1 labeled H2A proteins in a human U2OS nucleus (size $12 \mu \mathrm{m} \times 18 \mu \mathrm{m}$ ). A conventional epifluorescence image was experimentally recorded prior to the 2CLM measurement (Fig. 3A). The nucleoli can be clearly identified due to the lower content of $\mathrm{H} 2 \mathrm{~A}$ histone proteins. Due to the limited optical resolution no further details of the H2A distribution are apparent. The 2CLM data of the same nucleus are shown in Fig. 3B. A data stack consisting of 6000 individual images was recorded in four steps (1500 images acquired in each step due to the size of the PC memory) with a frame rate of about $16 \mathrm{~Hz}$. Mechanical drift of the sample was corrected by correlating the summed signal of each of those four stacks with the first one. The drift within one data stack was estimated to be $12 \mathrm{~nm}$ (see supplementary material). 
In every image the positions of the blinking mRFP1 molecules were determined as described in 2.3. The result is displayed in Fig. 3B: All 71156 registered positions of individual H2A-mRFP1 signals are plotted together and blurred with a Gaussian according to their localization accuracy. The mean localization accuracy was $\sigma=38 \mathrm{~nm}$ (see Fig. 6).

Figure 4 shows the distribution of GFP labeled Snf2H proteins in the same nucleus as above. Again a conventional epifluorescence image (Fig. 4A) was acquired before 2CLM imaging. Nucleoli cannot be identified in the epifluorescence nor the 2CLM image (Fig. 4). In total 4500 images were recorded in three stacks. From these, 47062 positions of Snf2H were determined with a mean localization accuracy of $\sigma=26 \mathrm{~nm}$ (see also Fig. 6).

In Fig. 5 the signal of both distributions is shown in the appropriate colors for comparison. The same structures are visible in the epifluorescence (Fig. 5A) and the 2CLM image (Fig. $5 B$ ). Autofluorescence from unlabeled structures is not present in the 2CLM image.

\subsection{Distribution analysis revealed partial colocalization between $\mathrm{H} 2 \mathrm{~A}$ and Snf2H}

To characterize the nuclear distributions of $\mathrm{H} 2 \mathrm{~A}$ and $\mathrm{Snf} 2 \mathrm{H}$, the number of neighbors of the same protein type within a $300 \mathrm{~nm}$ radius around each detected particle was determined in a typical cell and plotted into a histogram (Fig. 7A,B). As a reference, the same histogram was generated for random distributions with the corresponding particle densities. The histograms for the random distributions could be fitted with a single Gaussian, whereas the observed histograms for $\mathrm{H} 2 \mathrm{~A}$ and $\mathrm{Snf} 2 \mathrm{H}$ were broader and had to be fitted with the sum of two or three Gaussians. This reflects the heterogeneity in the $\mathrm{H} 2 \mathrm{~A}$ and $\mathrm{Snf} 2 \mathrm{H}$ density and the presence of low- and high-density populations for both $\mathrm{H} 2 \mathrm{~A}$ and Snf2H. To identify these regions of different particle density, different colors were assigned (Fig. 7C,D). The cut-off values were chosen to be the values at the intercept of the Gaussians used for fitting the corresponding histogram. In order to detect also locations with the highest protein density, the $10 \%$ of the particles with the largest number of neighbors were depicted in yellow. In the case of $\mathrm{H} 2 \mathrm{~A}$, the sparse regions contained the nucleoli as expected. However, additional regions which did not coincide with these nuclear compartments appeared to be $\mathrm{H} 2 \mathrm{~A}-$ poor. The high-density regions of H2A (labeled green/yellow in Fig. 7C), which comprised about $55 \%$ of the area of the cell nucleus, formed interconnected patches including mostly regions located in the centre of the nucleus. In the case of $\mathrm{Snf} 2 \mathrm{H}$, the sparse regions were found at the nuclear periphery. In the remaining part of the nucleus $\mathrm{Snf} 2 \mathrm{H}$ was distributed more homogeneously than $\mathrm{H} 2 \mathrm{~A}$. In contrast to the H2A distribution, the high-density regions of Snf2H (labeled green/yellow in Fig. 7D) comprised $36 \%$ of the area of the cell nucleus. In average, Snf2H molecules had $37 \pm 12$ neighbors, $\mathrm{H} 2 \mathrm{~A}$ molecules had $52 \pm 23$ neighbors (intervals include $68 \%$ of the molecules). Snf $2 \mathrm{H}$-rich regions were located near the centre of the nucleus and often but not always corresponded to H2A-rich regions (see arrows).

To analyze the colocalization of $\mathrm{H} 2 \mathrm{~A}$ and $\mathrm{Snf} 2 \mathrm{H}$, a correlation coefficient according to Pearson of $R=0.25$ was calculated for the images from Fig. 5 while $R=0.13-0.17$ was obtained for the random distributions. A value of 1 would represent perfect colocalization, $a$ value of -1 would represent perfect anti-colocalization. These results suggest a partial 
colocalization between $\mathrm{H} 2 \mathrm{~A}$ and $\mathrm{Snf} 2 \mathrm{H}$ that is compatible with transient interaction behavior of the two proteins detected in FRAP experiments (data not shown). Similar results were obtained by the analysis of the number of $\mathrm{Snf} 2 \mathrm{H}$ molecules around $\mathrm{H} 2 \mathrm{~A}$ in a typical cell and vice versa (Fig. 8). The average number of Snf2H molecules in the vicinity of $\mathrm{H} 2 \mathrm{~A}$ (50 molecules within $300 \mathrm{~nm}$ radius) was significantly larger than the average number of randomly distributed particles in the same region (41 molecules within $300 \mathrm{~nm}$ radius) as confirmed by a Kolmogorov-Smirnov test (see supplementary material); the same was true for $\mathrm{H} 2 \mathrm{~A}$ molecules in the vicinity of $\mathrm{Snf} 2 \mathrm{H}(33 \mathrm{H} 2 \mathrm{~A}$ molecules vs. 27 randomly distributed molecules within $300 \mathrm{~nm}$ radius). Further analysis of the histograms in Fig. 8 was indicative of the presence of two particle populations, one with a large number of neighbors and one with a small number of neighbors. Thus, the relative amounts of H2A and $\mathrm{Snf} 2 \mathrm{H}$ differ throughout the cell, suggesting the presence of chromatin regions with locally enriched Snf2H concentration.

\section{DISCUSSION}

For the better understanding of functional cellular nanostructures, there is an urgent need to circumvent the limitations of conventional light microscopy given by the Áb̄e/Rayleigh limit of optical resolution. Multiple approaches for light optical analysis of biostructures at enhanced resolution exist, with each of these having specific biological, biophysical and biomedical applications. Recently, various methods of spectrally assigned localization microscopy (SALM) have been shown to allow the nanoimaging of individual molecules at an optical resolution close to the dimensions of small proteins.

In this report, SPDM with conventional fluorochromes under special physical conditions was used to realize two color localization microscopy (2CLM). For each fluorochrome, only one wavelength was sufficient for $2 \mathrm{CLM}$. In this manner, the spatial distribution of two different molecule types with distinct fluorescence emission wavelengths was obtained. Under the conditions used (sampling time per image $60-100 \mathrm{~ms}$ ) the percentage of molecules appearing multiple times was estimated to be rather low. In previous publications registered under at least the same mechanical stability and registration/evaluation conditions [28], single molecule positions of fluorescent proteins can be distinguished outside the nucleus, i.e. at very low molecule densities. A major percentage of multiple appearance would have resulted in multiple small clusters. This was not observed. Furthermore, in the 2CLM images presented here, a major percentage of multiple appearance should be reflected in a strongly increased frequency of next neighbor distances (Fig. 8) which also was not observed.

Since biological specimens labeled with such fluorescent proteins are most common, 2CLM methods using such fluorochromes have a wide range of applications, including the potential for in vivo measurements in cell cultures. In particular, they offer unique possibilities for the functional characterization of molecular interactions between protein complexes. This is demonstrated in the present work for the determination of the spatial distribution of the Snf2H chromatin remodeler with respect to histone $\mathrm{H} 2 \mathrm{~A}$ as a nucleosome/chromatin marker. Although chromatin remodeling complexes have been shown in several studies to possess distinct nucleosome/DNA binding and remodeling 
capabilities in vitro (e.g. [39-42] and references therein), little is known on how they operate in the cell. In a previous pioneering study Varga-Weisz and colleagues used conventional confocal fluorescence microscopy at a lateral resolution of several $100 \mathrm{~nm}$ to study Snf2H and its associated Acf1 subunit [43]. Their work revealed the overall Snf2H/Acf1 nuclear distribution with an enrichment in pericentric heterochromatin foci present in mouse cells, which have typical diameters of $\sim 1 \mu \mathrm{m}$. 2CLM allowed an effective optical resolution that was better by an order of magnitude so that the light microscopic investigation of the interaction of $\mathrm{Snf} 2 \mathrm{H}$ and other chromosomal proteins on the level of a single nucleosome becomes feasible. We show how density maps with high resolution for two different proteins in the same specimen can be generated and used to derive information about the interaction behavior on different length scales (Fig. 8). On these images, regions of increased nucleosome density can be identified from the H2A-mRFP1 signal, which could represent higher order structures of the folded nucleosome chain. The $\mathrm{Snf} 2 \mathrm{H}$ remodeler is distributed more homogeneously suggesting that a significant fraction of $\mathrm{Snf} 2 \mathrm{H}$ is not associated permanently with chromatin consistent with fluorescence recovery after photobleaching experiments (Erdel \& Rippe, private communication). While the nuclear periphery was partially depleted from $\mathrm{Snf} 2 \mathrm{H}$ virtually all other nuclear regions, including the nucleolus, were accessible to the chromatin remodeler.

In Figure 7 several distinct regions with locally increased or decreased Snf2H density with respect to $\mathrm{H} 2 \mathrm{~A}$ density are present that reflect a spatially altered interaction behavior between Snf2H and H2A. In particular, several high-density Snf2H regions can be identified that do not coincide with a strong H2A signal. Since it is expected that this increased Snf2H density is connected with higher remodeling activity, these regions represent bona fide chromatin remodeling hot spots that are likely to be loci of a pronounced translocation of nucleosomes by Snf2H-containing molecular machines. Furthermore, sites of colocalization of $\mathrm{H} 2 \mathrm{~A}$ and $\mathrm{Snf} 2 \mathrm{H}$ are clearly present as inferred from the quantitative analysis (Fig. 8). The closely co-localizing signals of single Snf2H-GFP and H2A-mRFP1 proteins may be interpreted as complexes of Snf2H at a nucleosome. Thus, complexes of the chromatin remodeler with its substrate can be detected by 2CLM. Compared with Fluorescence Resonance Energy Transfer (FRET) methods, in addition to neighborhood estimates the 2CLM images allow such vicinity determinations of single complexes at distances not accessible to FRET procedures. Additionally, 2CLM methods provide "true optical resolution" in the region of about ten times better than conventional fluorescence microscopy techniques and thus give also the spatial position of such complexes even in a "crowded" nucleus. We anticipate that further studies along these lines in combination with quantitative image analysis will provide valuable information on the molecular details of nucleosome translocations by chromatin remodelers. Furthermore, the 2CLM investigations of other chromosomal proteins associated with the genome will serve to derive spatial molecular interaction maps for their organization in the nucleus.

At an effective optical resolution down to the $10-20 \mathrm{~nm}$ range laterally in an optical section of about $600 \mathrm{~nm}$ thickness, numerous other applications in the structural elucidation of cellular nanostructures are feasible. Examples for such nanostructures are individual gene domains in genetically active and inactive states [2], environmentally induced changes of 
chromatin nanostructure [16], size and nuclear distribution of transcription complexes [46, 47], replication factories [53] and repair complexes [45], nuclear pore complex distribution [48], arrangement of polyribosomes. An additional important application will be the possibility to count single molecules. Although the 2CLM technique allowed us to register only a part of all labeled molecules, the figures obtained are minimum absolute numbers. For example, a count of 90000 proteins in an optical section of a human fibroblast nucleus of $10 \times 10 \mu \mathrm{m}=100 \mu \mathrm{m}^{2}$ results in a molecule density of about $900 / \mu \mathrm{m}^{2}$. Even at the best corresponding conventional optical resolution only a few thousand molecules would be resolvable in a nuclear area of $100 \mu^{2}$, corresponding to a density of resolved molecules of about 30 molecules $/ \mathrm{um}^{2}$. Since many protein types in the cells occur in numbers in the order of $10^{4}$ to $10^{5}, 2$ CLM and related SALM methods for the first time promise to count fluorescently labeled molecules in the cell even at such high numbers and densities. Presently, the number of molecules counted is a relative number since it is not known to what percentage the molecules can be excited in the way required for this type of localization microscopy (which might be true also for other SALM methods). It is expected that by appropriate calibration methods, even absolute numbers of individual molecules will become countable, down to only a few molecules of a given type in an entire cell. If conditions can be realized to induce fluorescence in a substantial part of such molecules the sensitivity of this method might become superior even to techniques based on radioactive decay: To reliably determine the number of a few radioactively labeled molecules in a cell, one has to apply registration for at least several life times of the radioactive substance used for labeling. For radioactive elements used in biology and medicine, these times would be prohibitively long. In addition to an effective optical resolution in the macromolecular range, this will open perspectives for many additional applications on the single cell level, such as high precision monitoring of specific DNA sequence amplification, gene expression, fast counting of virus particles inside and outside cells at a spatial resolution equivalent to conventional electron microscopy, counting of proteins in intracellular normal and pathological aggregates, or counting of drug molecules present in specific nanoregions across the cell membrane.

\section{ACKNOWLEDGEMENTS}

The authors thank Prof. Markus Sauer (Bielefeld University), Dr. Michael Wassenegger (AIPlanta, Neustadt/Weinstraße) and Dr. Victor Sourjik (ZMBH, University of Heidelberg) for support. We are grateful to Patrick Varga-Weisz (Babraham Institute, Cambridge) for providing plasmid vectors. The financial support of the State of Baden-Württemberg and of the Deutsche Forschungsgemeinschaft (SPP1128) to both Christoph Cremer and Karsten Rippe (also grant Ri 1283/8-1) and of the European Union (In Vivo Molecular Imaging Consortium, www.molimg.gr) is gratefully acknowledged. We also thank our colleagues Thibaud Jegou, Thomas Ruckelshausen, David Baddeley, Jürgen Reymann, Alexander Brunner, Alexa von Bassewitz, Heinz Eipel and Margund Bach for great support. Paul Lemmer is a Ph.D. student fellow of the Hartmut HoffmannBerling International Graduate School of Molecular and Cellular Biology of the University of Heidelberg and a member of the Excellence Cluster Cellular Networks of the University of Heidelberg; Rainer Kaufmann is a Ph.D. student fellow in a Frontierproject of the Marsilius College University Heidelberg. 


\section{REFERENCES}

(1) Cremer, T., Von der Zellenlehre zur Chromosomentheorie, Springer-Verlag Berlin Heidelberg 1985 Download: http://humangenetik.bio.Imu.de/service/downloads/buch tc/index.html.

(2) Cremer, T., Cremer, C., Chromosome territories, nuclear architecture and gene regulation in mammalian cells,. Nature Reviews Genetics 2001, 2, 292-301.

(3) Abbe, E., Beiträge zur Theorie des Mikroskops und der mikroskopischen Wahrnehmung. Archiv f. mikroskopische Anatomie 1873, 9, 411-468.

(4) Rayleigh, L., On the theory of optical images, with special reference to the microscope. Philosophical Magazine 1896, 42(5), 167-195.

(5) Hell, S.W., Lindek, S., Cremer, C., Stelzer, E.H.K., Measurement of the 4Pi-confocal point spread function proves $75 \mathrm{~nm}$ axial resolution. Applied Physics Letters 1994, 64, 1335.

(6) Hell, S.W., Toward fluorescence nanoscopy. Nature Biotechnology 2003, 2 (11), 1347-1355.

(7) Heintzmann, R., Cremer, C., Lateral modulated excitation microscopy: Improvement of resolution by using a diffraction grating. Proc. SPIE 1999, 356, 185-196.

(8) Gustafsson, M., Shao, L., Carlton, P.M., Wang, C.J.R. et al., Three-Dimensional Resolution Doubling in Wide-Field Fluorescence Microscopy by Structured Illumination. Biophysical Journal 2008, 94(12). 4957-4970.

(9) Hell, S.W., Far-Field Optical Nanoscopy. Science 2007, 316(5828), 1153-1158.

(10) Schmidt, R., Egner, A., Hell, SW, isoSTED Microscopy. Frontiers in Optics 2008.

(11) Bornfleth, H., Sätzler, E.H.K, Eils, R., Cremer, C. High-precision distance measurements and volumeconserving segmentation of objects near and below the resolution limit in three-dimensional confocal fluorescence microscopy. Journal of Microscopy 1998, 189(2), 118-136.

(12) Cremer, C. et al., German Patent Application No. 196.54.824.1/DE, submitted Dec 23, 1996, European Patent EP 1997953660, 08.04.1999, Japanese Patent JP 1998528237, 23.06.1999, United States Patent US 09331644, 25.08.1999

(13) Heilemann, M., Herten, D.P., Heintzmann, R., Cremer, C. et al., High-resolution colocalization o single dye molecules by fluorescence lifetime' imaging microscopy. Analytical Chemistry 2002, 74(14), 3511-3517.

(14) Cremer, C., Edelmann, P., Bornfleth, H., Kreth, G. et al., Principles of Spectral Precision Distance confocal microscopy for the analysis of molecular nuclear structure, in: Jähne, B. (Ed.), Haußecker, H. (Ed.), Geißler, P. (Ed.), Handbook of Computer Vision and Applications, Academic Press, Inc Orlando 1999, pp. 839-857.

(15) Edelmann, P., Esa, A., Hausmann M., Cremer, C., Confocal laser scanning microscopy: In situ determination of the confocal point-spread function and the chromatic shifts in intact cell nuclei. Optik 1999, 110, 194-198.

(16) Esa, A, Edelmann, P., Kreth, G., Trakhtenbrot, L. et al., Three-dimensional spectral precision distance microscopy of chromatin nanostructures after triple-colour DNA labelling: a study of the BCR region on chromosome 22 and the Philadelphia chromosome. Journal of Microscopy 2000, 199(2) 96-105.

(17) Lacoste, T.D., Michalet, X., Pinaud, F., Chemla, D.S. et al., Ultrahigh-resolution multicolor colocalization of single fluorescent probes. 2000, 97(17), 9461-9466. 
1

2

3

4

5

6

7

8

9

10

11

12

13

14

(18) Schmidt, M., Nagorni, M., Hell, S.W., Subresolution axial distance measurements in far-fiele fluorescence microscopy with precision of 1 nanometer. Review of Scientific Instruments 2000, 71 2742.

(19) Rauch J., Hausmann M., Solovei, I., Horsthemke B. et al., Measurement of local chromatin compaction by Spectral Precision Distance microscopy. Proc. SPIE 2000, 4164, 1-9.

(20) Betzig, E., Patterson, G.H., Sougrat, R., Lindwasser, O.W. et al., Imaging Intracellular Fluorescent Proteins at Nanometer Resolution. Science 2006, 313(5793), 1642-1645.

(21) Hess, S., Girirajan, T., Mason, M. Ultra-High Resolution Imaging by Fluorescence Photoactivation Localization Microscopy. Biophysical Journal 2006, 91(11), 4258-4272.

(22) Rust, M., Bates, M., Zhuang, X., Sub-diffraction-limit imaging by stochastic optical reconstruction microscopy (STORM). Nature Methods 2006, 3, 793-795.

(23) Egner, A., Geisler, C., von Middendorff, C., Bock, H. et al., Fluorescence nanoscopy in whole cells by by asynchronous localization of photoswitching emitters. Biophysical Journal 2007, 93, 3285-3290.

(24) Andresen, M., Stiel, A.C., Jonas, F., Wenzel, D. et al., Photoswitchable fluorescent proteins enable monochromatic multilabel imaging and dual color fluorescence nanoscopy. Nature Biotechnology 2008, 26 (9), 1035-1040.

(25) Reymann, J., Baddeley, D., Gunkel, M., Lemmer, P. et al., High-precision structural analysis o subnuclear complexes in fixed and live cells via spatially modulated illumination (SMI) microscopy Chromosome Research 2008, 16(3), 367-382.

(26) Lemmer, P., Gunkel, M., Baddeley, D., Kaufmann, R. et al., SPDM: Light microscopy with singlemolecule resolution at the nanoscale. Applied Physics B 2008, 93(1), 1-12.

Lemmer P., C. Cremer, D. Baddeley, H. Eipel, Procedure and setup for localization of single fluorophores in fluorescence microscopy, German Patent Application, submitted March 19, 2008.

(27) Heilemann M., van de Linde S., Schuttpelz M., Kasper R. et al., Subdiffraction-Resolution Fluorescence Imaging withConventional Fluorescent Probes. Angew. Chemie 2008, Int. Ed 47, 6172 $-6176$.

(28) R. Kaufmann, P. Lemmer, M. Gunkel, Y. Weiland et al., SPDM - Single Molecule Superresolution of Cellular Nanostructures. Proc. SPIE 2009, 7185, 71850J.

(29) Burns, D.H., Callis, J.B., Christian, G.D., Davidson, E.R., Strategies for attaining superresolution using spectroscopic data as constraints. Applied Optics 1985, 24 (2), 154-161.

(30) Betzig, E., Proposed method for molecular optical imaging. Optics Letters 1995, 20, 237.

(31) van Oijen, A.M., Köhler, J., Schmidt, J., Müller, M. et al., 3-Dimensional super-resolution by spectrally selective imaging. Chemical Physics Letters 1998, 192(1-2), 182-187.

(32) Cremer, C., Failla,. A., V., Albrecht, B., United States Patent No. US 7,298,461 B2 submitted Oct 9 , 2001.

(33) Cremer, C., German Patent Application 2116521, (1971).

(34) Sinnecker, D., Voigt, P., Hellwig, N., Schaefer, M., Reversible photobleaching of enhanced green fluorescent proteins. Biochemistry 2005, 44 (18), 7085-7094.

(35) Patterson, G.H., Lippincott-Schwartz, J., A Photoactivatable GFP for Selective Photolabeling of Proteins and Cells. Science 2002, 297 (5588), 1873-1877.

(36) Hendrix, J., Flors, C., Dedecker, P., Hofkens, J. et al., Dark States in Monomeric Red Fluorescent Proteins Studied by Fluorescence Correlation and Single Molecule Spectroscopy. Biophysical Journal 2008, 94 (10), 4103. 
(37) Baddeley D. , Jayasinghe I.D., Cremer C. , Cannell M.B. et al., Light-induced dark states of organic fluorochromes enable $30 \mathrm{~nm}$ resolution imaging in standard media. Biophysical J., in press.

(38) van Holde, K.E. Chromatin, Springer, Heidelberg 1989.

(39) Becker, P.B., Horz, W., ATP-dependent nucleosome remodeling. Annu Rev Biochem 2002, 71, 247273.

(40) Cairns, B.R., Chromatin remodeling: insights and intrigue from single-molecule studies. Nat Struct $\mathrm{Mol}$ Biol 2007, 14, 989-996.

(41) Rippe, K., Schrader, A., Riede, P., Strohner, R., et al., DNA sequence- and conformation-directec positioning of nucleosomes by chromatin-remodeling complexes. Proc. Natl. Acad. Sci. USA 2007, $104,15635-15640$.

(42) Langst, G., Becker, P.B., Nucleosome mobilization and positioning by ISWI-containing chromatinremodeling factors. J. Cell Sci. 2001, 114, 2561-2568.

(43) Collins, N., Poot, R.A., Kukimoto, I., Garcia-Jimenez, C. et al., An ACF1-ISWI chromatin-remodeling complex is required for DNA replication through heterochromatin. Nat. Genet. 2002,32, 627-632.

(44) Lemmer P., Gunkel M., Baddeley D., Kaufman R. et al., Using conventional fluorescent markers for far-field fluorescence nanoscopy allows resolution in the $10 \mathrm{~nm}$ range. revised version submitted.

(45) Hauptner, A., Krucken, R., Greubel, C., Hable, V. et al., DNA-repair protein distribution along the tracks of energetic ions. Radiation protection dosimetry 2006, 122, 147-149.

(46) Rauch J., Knoch T.A., Solovei I., Teller K. et al., Lightoptical precision measurements of the active and inactive Prader-Willi Syndrome imprinted regions in human cell nuclei. Differentiation 2008, 76: 66-83.

(47) Martin S., Failla A.V., Spoeri U., Cremer C. et al., Measuring the Size of Biological Nanostructures with Spatially Modulated Illumination Microscopy. Molecular Biology of the Cell 2004, 15: 2449-2455.

(48) Schermelleh, L., Carlton, P.M., Haase, S., Shao, L. et al., Subdiffraction multicolor imaging of the nuclear periphery with $3 d$ structured illumination microscopy, Science 2006, 320, 1332-1336.

(49) Fölling, J., Bossi, M., Bock, H., Medda, R. et al., Fluorescence nanoscopy by ground-state depletion and single-molecule return. Nature Methods 2008, 5(11), 943-945.

(50) S. van de Linde, M Sauer, M Heilemann, Subdiffraction-resolution fluorescence imaging of proteins in the mitochondrial inner membrane with photoswitchable fluorophores. Journal of Structural Biology $2008,164,250-254$.

(51) S. van de Linde, R Kasper, M Heilemann, M Sauer, Photoswitching microscopy with standaro fluorophores. Applied Physics B 2008, 93, 725-731.

(52) Rittweger, E., Han, K.Y., Irvine, S.E., Eggeling, C. et al., STED microscopy reveals crystal colour centres with nanometric resolution. Nature Photonics 2009, 3, 144-147.

(53) Leonhardt, H., Rahn, H.P., Weinzierl, P., Sporbert, A. et al., Dynamics of DNA replication factories in living cells, Journal of Cell Biology 2000,149, 271-280.

\section{Figure Legends:}

Figure 1. Microscope setup. Schematic representation of the microscopic setup for 2 CLM. DM1, DM2: dichroic elements, L1 - L4: lenses or lens systems, BF1 (interchangeable 
blocking filter): dichroic elements to block the illumination light (488 nm, $568 \mathrm{~nm}$ ). GFP fluorescence emission (emission maximum @ $\mathrm{\lambda em}=520 \mathrm{~nm}$ ) is transmitted through a bandpass filter (HQ 525/50), mRFP1 fluorescence emission (emission maximum @ $@$ em = $584 \mathrm{~nm})$ is transmitted through a triple line blocking filter (488/568/647nm). From Lemmer et al. 2009 [44].

Figure 2. Simulation of 2CLM. First row: Dual color object in three different label densities (left: 50000 molecules $/ \mu \mathrm{m}^{2}$, middle: 5000 molecules $/ \mu \mathrm{m}^{2}$, right: 500 molecules $/ \mu \mathrm{m}^{2}$ ) is imaged using different assumptions. Second row: Conventional epifluorescence microscopy with NA 1.4, $100 \mathrm{~nm}$ pixel size, $520 \mathrm{~nm} / 580 \mathrm{~nm}$ emission wavelength. The size of the scalebar is $500 \mathrm{~nm}$. Third row: 2CLM image with $20 \mathrm{~nm}$ mean localization accuracy. Last row: 2CLM image with $10 \mathrm{~nm}$ mean localization accuracy. The single molecule positions in the 2CLM images are blurred with a Gaussian kernel corresponding to the estimated mean localization accuracy of the process.

Figure 3. Distribution of $\mathrm{H} 2 \mathrm{~A}$ proteins within a human U2OS nucleus. (A) Conventional epifluorescence image. (B) 2CLM image, each mRFP1-position is blurred with a Gaussian representing the individual localization accuracy. Panel $C$ and $D$ display enlarged regions. Scale bars are $2 \mu \mathrm{m}$ in $A$ and $B$ and $500 \mathrm{~nm}$ in $C$ and $D$.

Figure 4. Distribution of Snf2H proteins within a human U2OS nucleus. (A) Conventional epifluorescence image. (B) 2CLM image, each GFP-position is blurred with a Gaussian representing the individual localization accuracy. Panel $C$ and $D$ display enlarged regions. Scale bars are $2 \mu \mathrm{m}$ in $A$ and $B$ and $500 \mathrm{~nm}$ in $C$ and $D$.

Figure 5. Distribution of $\mathrm{H} 2 \mathrm{~A}$ proteins (red) and Snf2H proteins (green) within a human U2OS nucleus. (A) Conventional epifluorescence image. (B) 2CLM image, each fluorochrome-position is blurred with a Gaussian representing the individual localization accuracy. Panel $C$ and D display enlarged regions. Scale bars are $2 \mu \mathrm{m}$ in $A$ and $B$ and 500 $\mathrm{nm}$ in $\mathrm{C}$ and $\mathrm{D}$.

Figure 6. Localization accuracy. (A) Histogram of localization accuracies of GFP and mRFP1 for one cell determined by the fitting algorithm. The lower accuracy for mRFP1 (38 $\pm 4 \mathrm{~nm}$ ) was due to a lower number of photon counts (see supplementary material). (B) Comparison of conventional epifluorescence and 2CLM image. In the latter one, two molecule positions with a distance of about $30 \mathrm{~nm}$ can be resolved (both recorded within 7 $\mathrm{s}$, corresponding to an estimated drift of about $1 \mathrm{~nm}$ ). The pixel size in the epifluorescence image is $65 \mathrm{~nm}$. 
Figure 7. Visualization of particle densities. A histogram of the number of neighbors (of the same color) within a circle of $300 \mathrm{~nm}$ radius was plotted for $\mathrm{H} 2 \mathrm{~A}(\mathrm{~A})$ and $\mathrm{Snf} 2 \mathrm{H}(\mathrm{B})$ for the cell below. As a reference, the same histograms were plotted for random distributions with equal particle densities. Experimentally observed histograms were broader than the histograms for random distributions and could only be fitted considering different particle populations. Based on these histograms, density maps for $\mathrm{H} 2 \mathrm{~A}(\mathrm{C})$ and $\mathrm{Snf} 2 \mathrm{H}$ (D) were derived to separate particles in the low-density population (blue/red), the high-density population (green) and the densest $10 \%$ (yellow). Arrows in panel $\mathrm{C}$ highlight regions of colocalization between $\mathrm{H} 2 \mathrm{~A}$ and $\mathrm{Snf} 2 \mathrm{H}$, arrows in panel $\mathrm{D}$ highlight regions of anticolocalization.

Figure 8. Colocalization analysis of $\mathrm{H} 2 \mathrm{~A}$ and $\mathrm{Snf} 2 \mathrm{H}$. For $\mathrm{H} 2 \mathrm{~A}(\mathrm{~A})$ and $\mathrm{Snf} 2 \mathrm{H}(\mathrm{D})$ in a typical cell a histogram of the distance to the nearest neighbor in the other color was plotted. Based on the average distances, two length-scales were chosen for which the number of different colored neighbors was shown in a histogram (B, C, E, F). As a reference, the number of neighbors in a random distribution with corresponding densities is shown. Experimentally observed histograms were broader than the histograms for random distributions, reflecting the heterogeneity of the density. Furthermore, the average number of neighbors is larger than for a random distribution, suggesting partial colocalization between $\mathrm{H} 2 \mathrm{~A}$ and $\mathrm{Snf} 2 \mathrm{H}$. 
obj:Figure 1: Microscope setup. Schematic representation of the microscopic setup for 2 CLM. DM1, DM2: dichroic elements, L1 - L4: lenses or lens systems, BF1 (interchangeable blocking filter): dichroic elements to block the illumination light (488 nm, $568 \mathrm{~nm})$. GFP fluorescence emission (emission maximum @ $\lambda$ em $=520 \mathrm{~nm}$ ) is transmitted through a bandpass filter (HQ 525/50), mRFP1 fluorescence emission (emission maximum @ $\lambda \mathrm{em}=584 \mathrm{~nm}$ ) is transmitted through a triple line blocking filter (488/568/647nm). From Lemmer et al. 2009 [44].

\section{$99 \times 84 \mathrm{~mm}(300 \times 300$ DPI $)$}



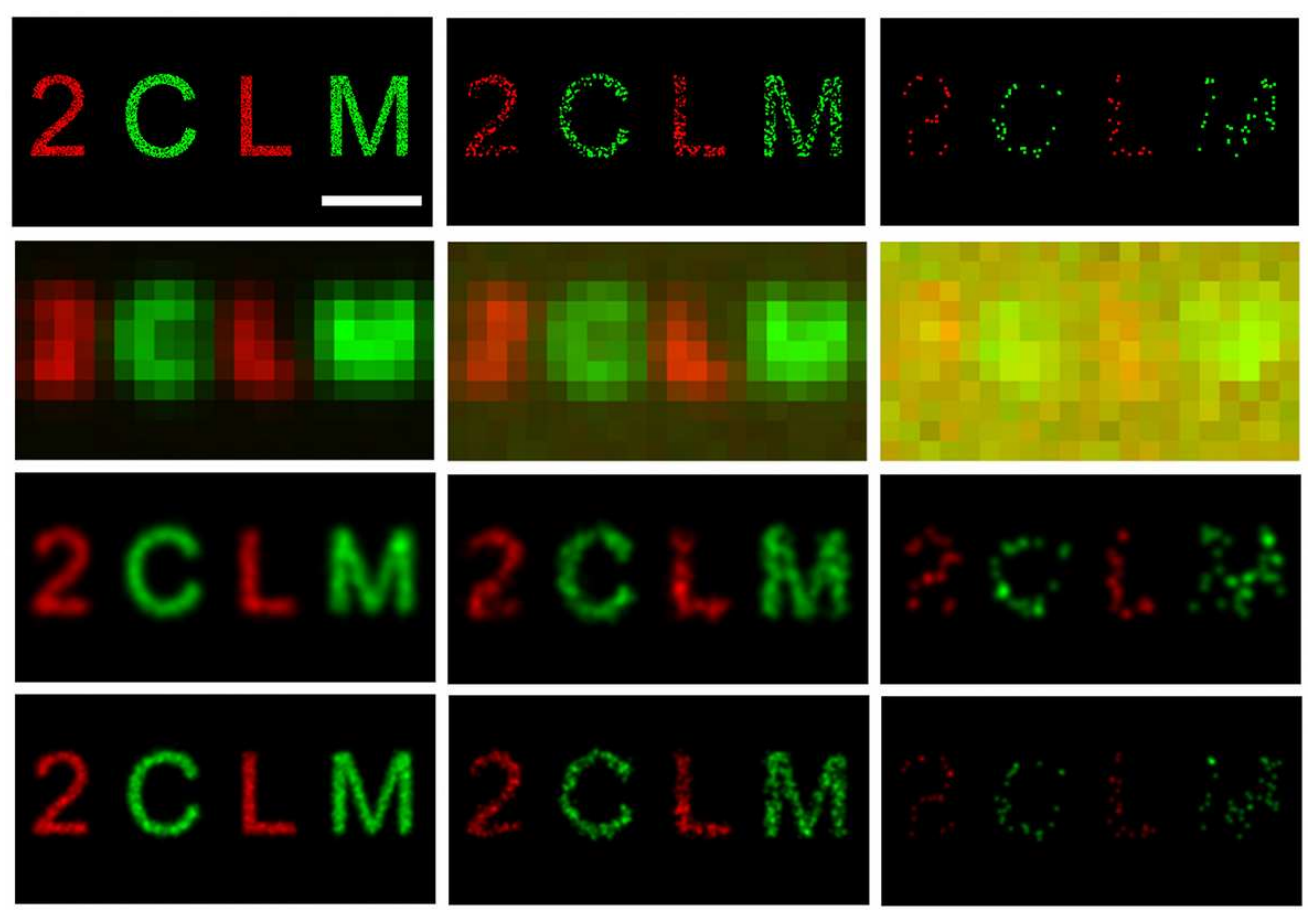

:oibifigure 2: Simulation of 2CLM. First row: Dual color object in three different label densities (left: 50000 molecules $/ \mu \mathrm{m}^{2}$, middle: 5000 molecules $/ \mu \mathrm{m}^{2}$, right: $500 \mathrm{molecules} / \mu \mathrm{m}^{2}$ ) is imaged using different assumptions. Second row: Conventional epifluorescence microscopy with NA 1.4, $100 \mathrm{~nm}$ pixel size, $520 \mathrm{~nm} / 580 \mathrm{~nm}$ emission wavelength. The size of the scalebar is $500 \mathrm{~nm}$. Third row:

2CLM image with $20 \mathrm{~nm}$ mean localization accuracy. Last row: 2CLM image with $10 \mathrm{~nm}$ mean localization accuracy. The single molecule positions in the 2CLM images are blurred with a Gaussian kernel corresponding to the estimated mean localization accuracy of the process. $99 \times 69 \mathrm{~mm}(300 \times 300 \mathrm{DPI})$ 

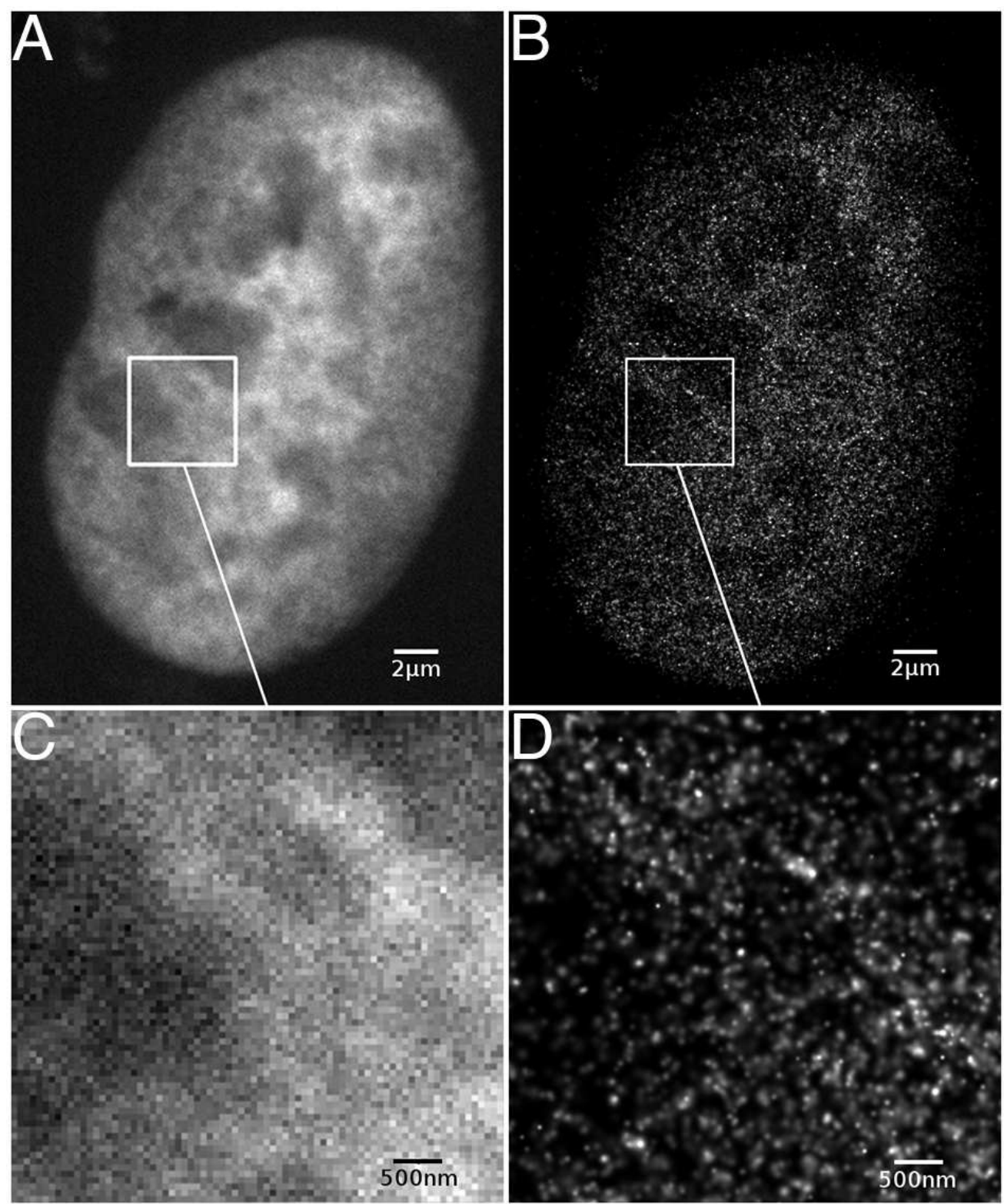

Figure 3: Distribution of $\mathrm{H} 2 \mathrm{~A}$ proteins within a human U2OS nucleus. (A) Conventional epifluorescence image. (B) 2CLM image, each mRFP1-position is blurred with a Gaussian representing the individual localization accuracy. Panel $C$ and $D$ display enlarged regions. Scale bars are $2 \mu \mathrm{m}$ in $A$ and $B$ and $500 \mathrm{~nm}$ in $C$ and $D$. $80 \times 96 \mathrm{~mm}(300 \times 300$ DPI $)$ 


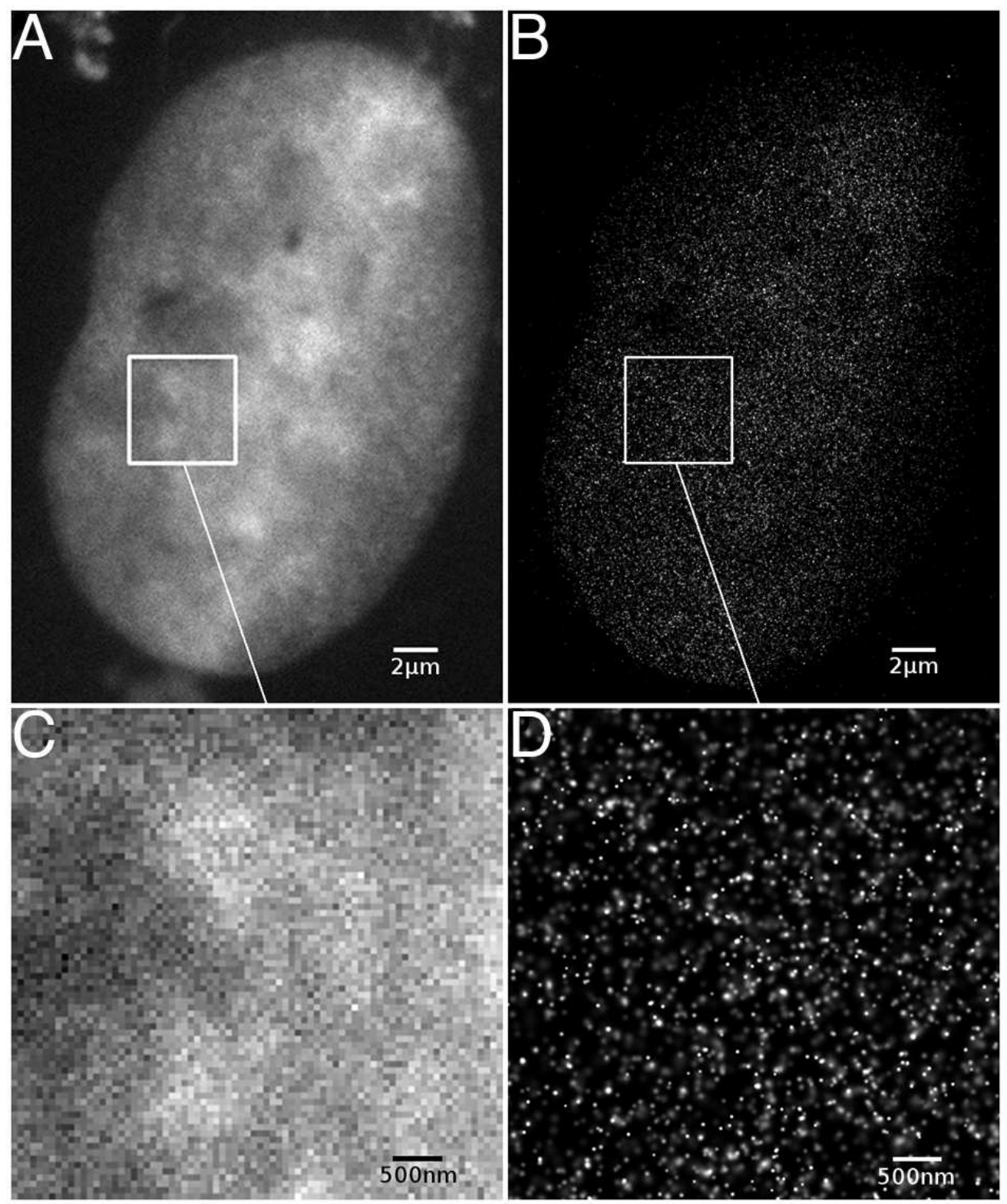

oij:igure 4: Distribution of Snf2H proteins within a human U2OS nucleus. (A) Conventional epifluorescence image. (B) 2CLM image, each GFP-position is blurred with a Gaussian representing the individual localization accuracy. Panel $C$ and $D$ display enlarged regions. Scale bars are $2 \mu \mathrm{m}$ in $A$ and $B$ and $500 \mathrm{~nm}$ in $C$ and $D$. $80 \times 96 \mathrm{~mm}(300 \times 300 \mathrm{DPI})$ 


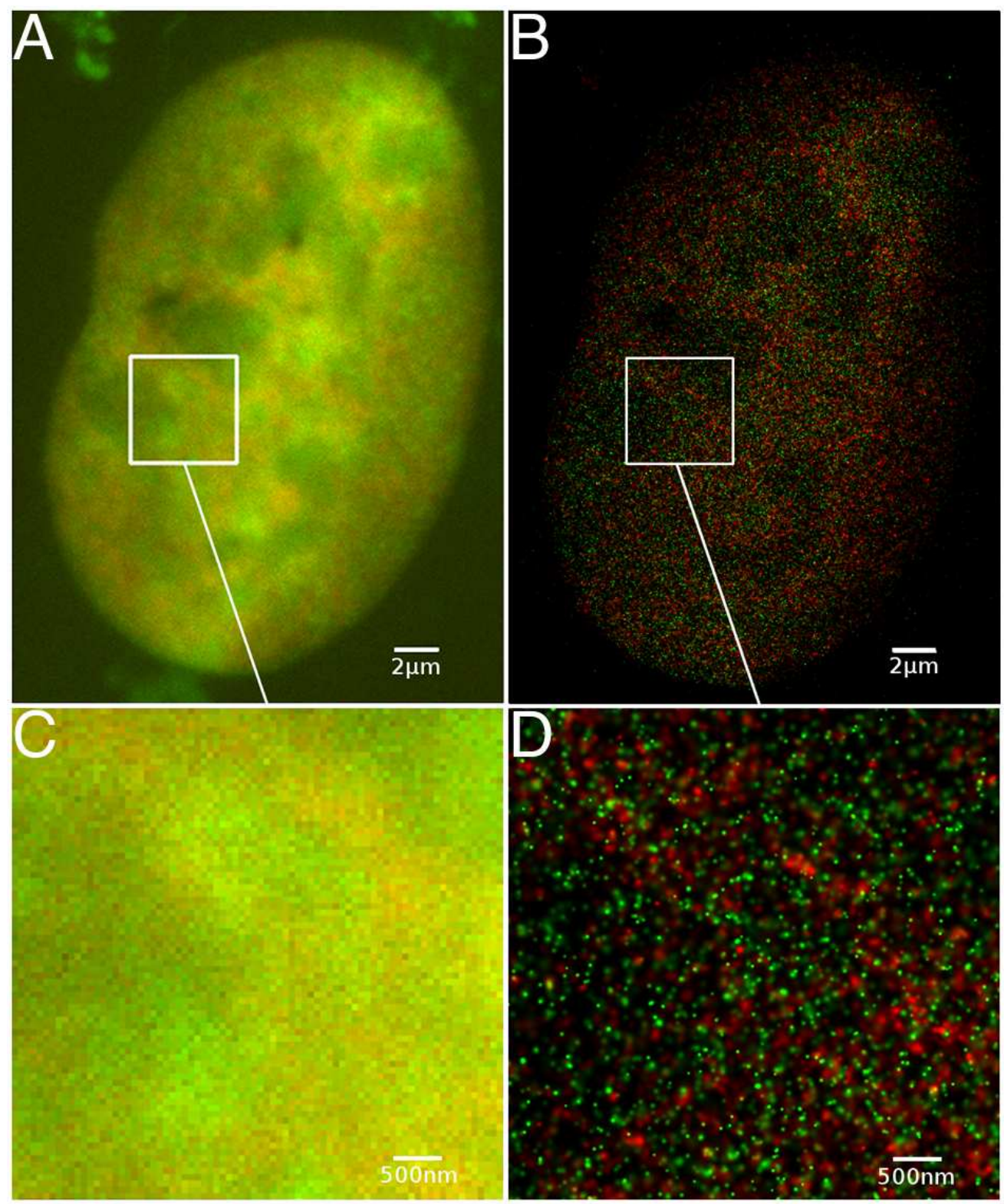

:öififigure 5: Distribution of $\mathrm{H} 2 \mathrm{~A}$ proteins (red) and $\mathrm{Snf} 2 \mathrm{H}$ proteins (green) within a human U2OS nucleus. (A) Conventional epifluorescence image. (B) 2CLM image, each fluorochrome-position is blurred with a Gaussian representing the individual localization accuracy. Panel $C$ and $D$ display enlarged regions. Scale bars are $2 \mu \mathrm{m}$ in $A$ and $B$ and $500 \mathrm{~nm}$ in C and D. $80 \times 96 \mathrm{~mm}(300 \times 300 \mathrm{DPI})$ 

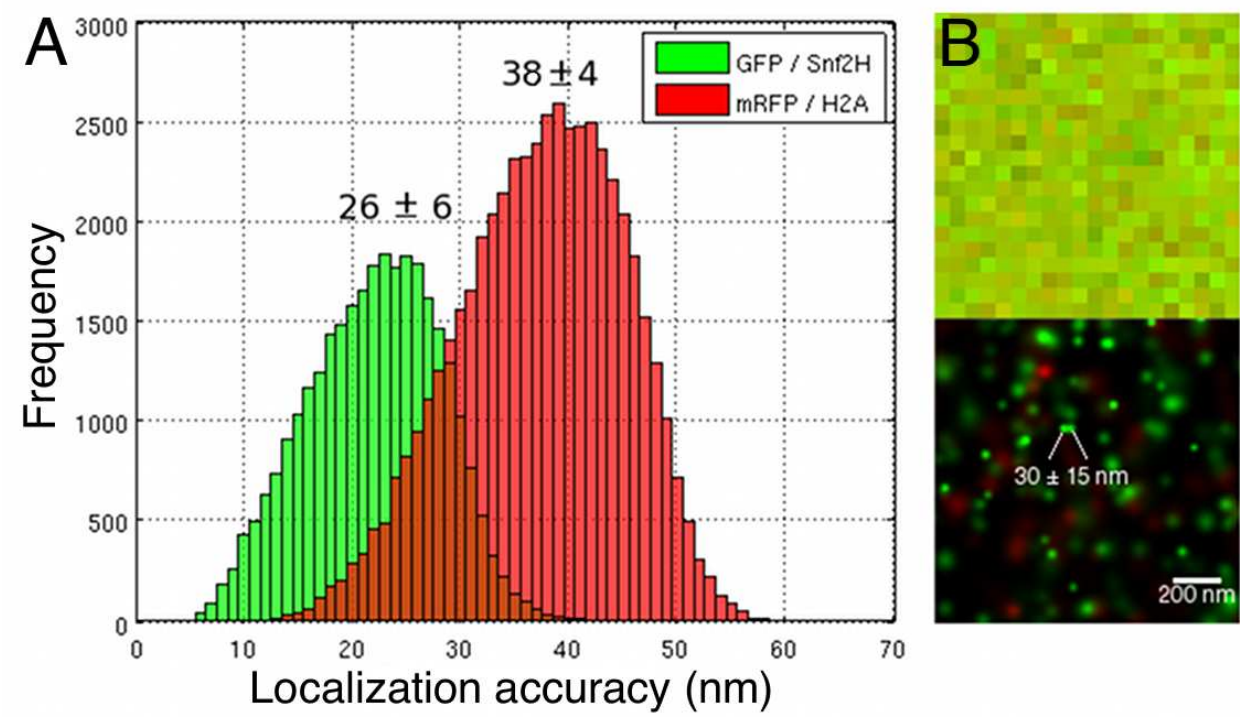

Oosigigure 6: Localization accuracy. (A) Histogram of localization accuracies of GFP and mRFP1 for one cell determined by the fitting algorithm. The lower accuracy for mRFP1 (38 $\pm 4 \mathrm{~nm}$ ) was due to a lower number of photon counts (see supplementary material). (B) Comparison of conventional epifluorescence and 2CLM image. In the latter one, two molecule positions with a distance of about $30 \mathrm{~nm}$ can be resolved (both recorded within $7 \mathrm{~s}$, corresponding to an estimated drift of about 1 $\mathrm{nm})$. The pixel size in the epifluorescence image is $65 \mathrm{~nm}$.

\section{$99 \times 55 \mathrm{~mm}(300 \times 300 \mathrm{DPI})$}



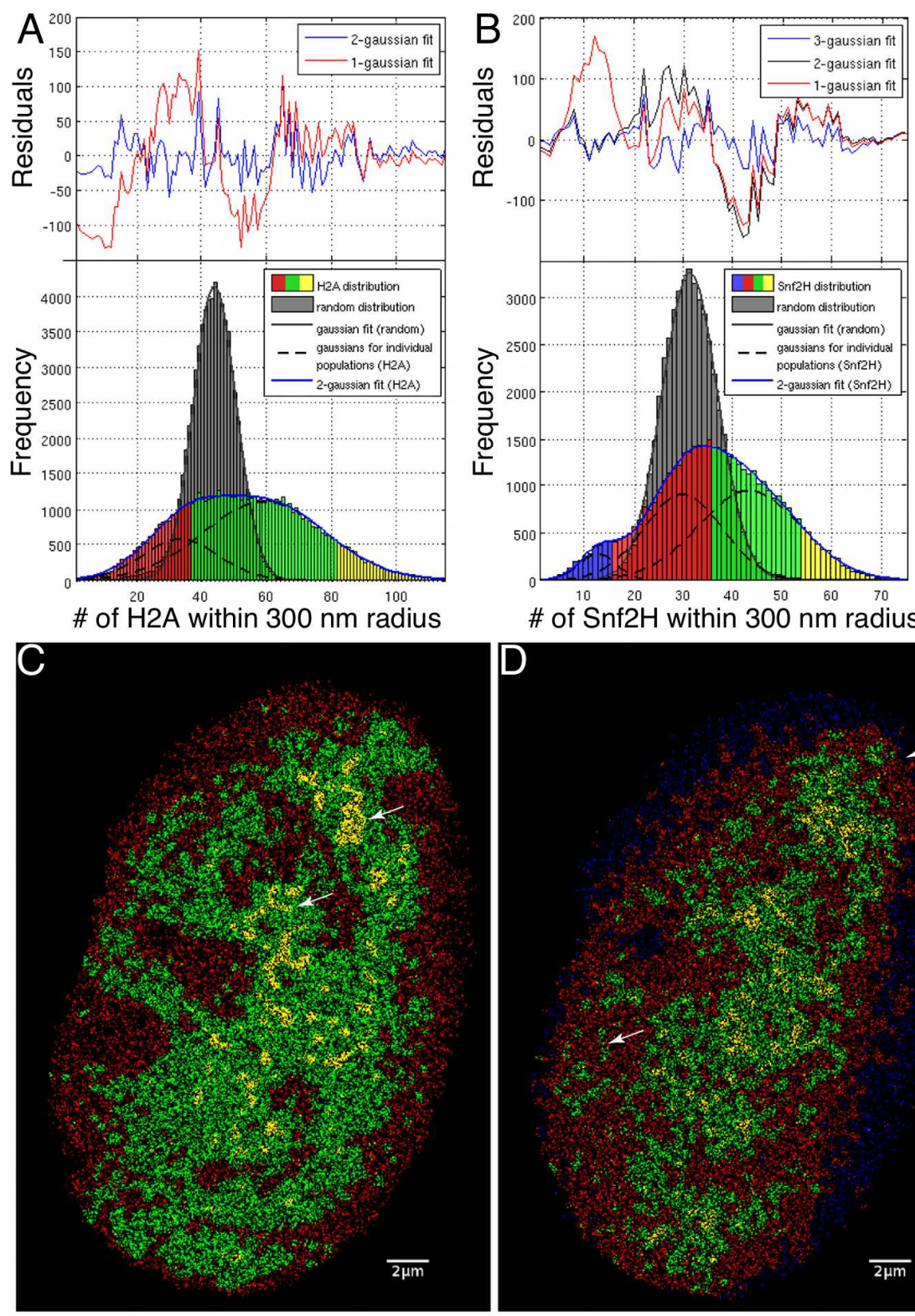

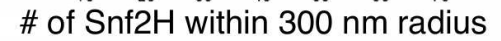

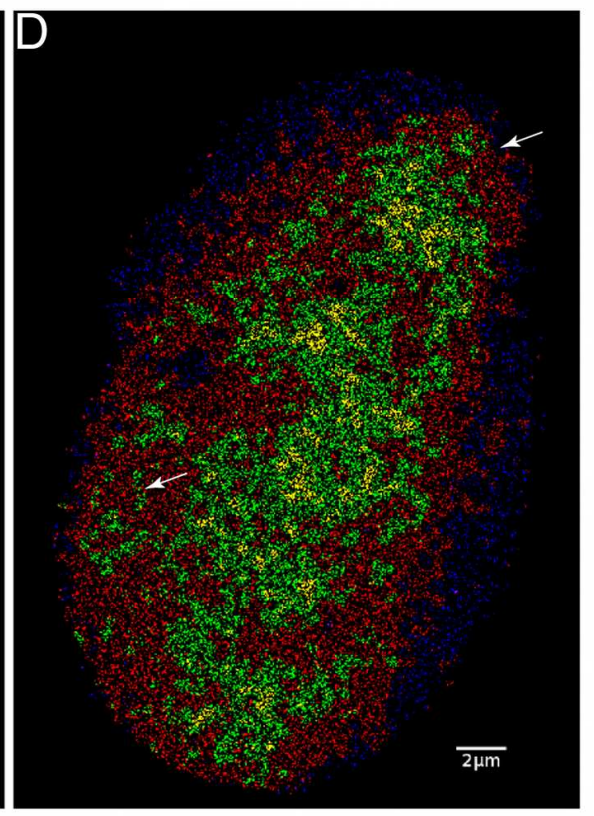

Figure 7: Visualization of particle densities. A histogram of the number of neighbors (of the same color) within a circle of $300 \mathrm{~nm}$ radius was plotted for $\mathrm{H} 2 \mathrm{~A}(\mathrm{~A})$ and $\mathrm{Snf} 2 \mathrm{H}(\mathrm{B})$ for the cell below. As a reference, the same histograms were plotted for random distributions with equal particle densities. Experimentally observed histograms were broader than the histograms for random distributions and could only be fitted considering different particle populations. Based on these histograms, density maps for H2A (C) and Snf2H (D) were derived to separate particles in the lowdensity population (blue/red), the high-density population (green) and the densest $10 \%$ (yellow). Arrows in panel $\mathrm{C}$ highlight regions of colocalization between $\mathrm{H} 2 \mathrm{~A}$ and $\mathrm{Snf} 2 \mathrm{H}$, arrows in panel D highlight regions of anti-colocalization. $119 \times 160 \mathrm{~mm}(300 \times 300$ DPI $)$ 

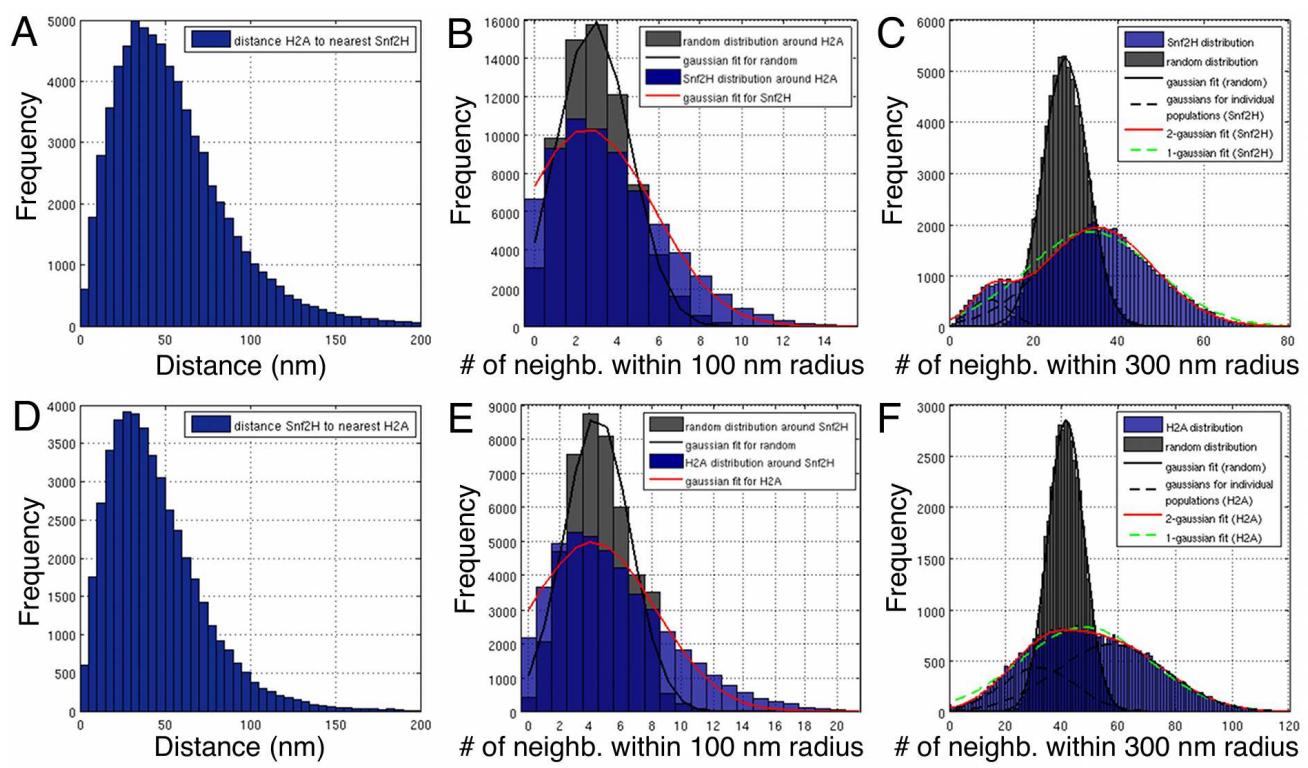

Figure 8: Colocalization analysis of $\mathrm{H} 2 \mathrm{~A}$ and $\mathrm{Snf} 2 \mathrm{H}$. For $\mathrm{H} 2 \mathrm{~A}(\mathrm{~A})$ and $\mathrm{Snf} 2 \mathrm{H}(\mathrm{D})$ in a typical cell a histogram of the distance to the nearest neighbor in the other color was plotted. Based on the average distances, two length-scales were chosen for which the number of different colored neighbors was shown in a histogram (B, C, E, F). As a reference, the number of neighbors in a random distribution with corresponding densities is shown. Experimentally observed histograms were broader than the histograms for random distributions, reflecting the heterogeneity of the density. Furthermore, the average number of neighbors is larger than for a random distribution, suggesting partial colocalization between $\mathrm{H} 2 \mathrm{~A}$ and $\mathrm{Snf} 2 \mathrm{H}$.

$160 \times 93 \mathrm{~mm}(300 \times 300 \mathrm{DPI})$ 